\title{
When You Feel That EVERYthING Is WRONG BUT NOTHING IS
}

\section{RAFAEL S.W.}

\section{Check Facebook.}

Play some different music. Louder.

Call your friends. From the window. Out

the balcony and into a starless night. You have

none. This is not your fault or problem or day. Listen

to the same three notes over and over and call it a song.

It's your heartbeat. It won't stop until you do. Flinch first.

Call the ambulance and then hang up saying nothing. Run.

There's no solution. You're cold all the time. People keep

asking if you're sick even though the doctor said you

weren't. Get tired of songs you used to cry to. Cry

for no reason in front of the television. Silently judged by no-hopers voted off with more talent than you'll ever have. Never know a full lung of air. Save in the drowning dreams. Smile.

Check Facebook. 